\title{
ENTREVISTA
}

\author{
Antonia Taulis \\ Josefina Guilisasti
}

\section{Josefina Guilisasti. La resignificación de la pintura}

*Entrevista jun 3, 2016 | Media Partner

\section{Resumo}

A entrevista realizada por Antonia Taulis com a artista chilena Josefina Guilisasti permite ao leitor uma aproximação com o processo de criação da artista.

Guilisasti nos fala sobre o contexto artístico em que se formou e que está hoje inserida, sobre como e por quê escolhe suas imagens e como se relaciona com a teoria e história da arte e da cultura. Debatendo sobre essas questões, Taulis e Guilisasti discutem sobre a ressignificação da pintura no processo da artista.

\section{Palavras-chave}

Pintura. História da arte e da cultura. Gêneros pictóricos. 
ENTREVISTA
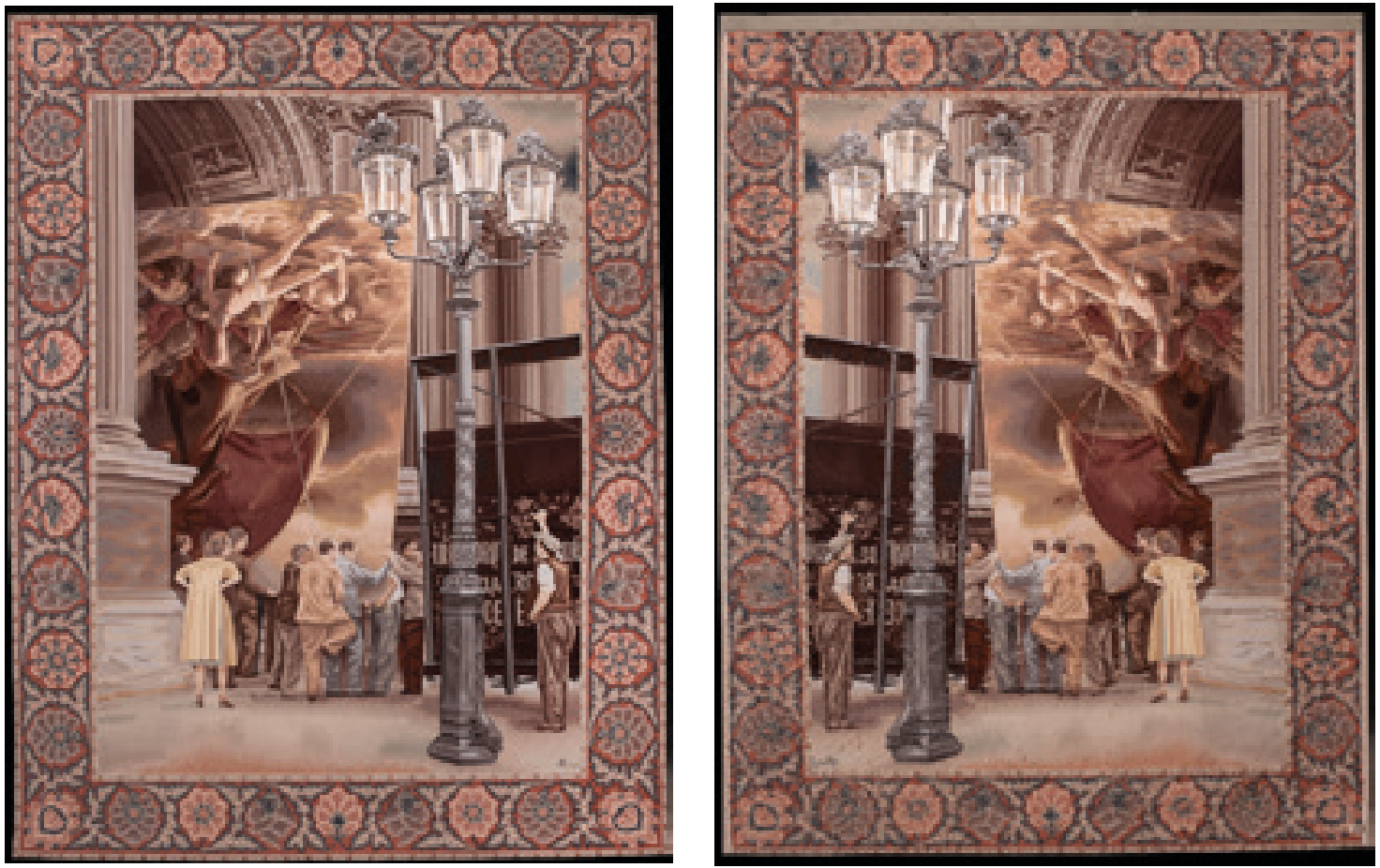

Figura 1. Josefina Guilisasti, en su tapiz titulado La Balsa de la Medusa (3,26 x 2,50 mtrs), pone en sincronía tres temporalidades distintas, pues la obra de Géricault dialoga con el peligro que implicó para el arte la Segunda Guerra Mundial, mientras que estos dos elementos a su vez, se tensionan con el soporte mismo que se ha escogido, un textil a la usanza barroca. Esta obra fue mandada a tejer a los talleres de la Galería Robert Four, Francia. Fonte: https://josefinaguilisasti.cl/La-Balsa-dela-Medusa
Con Josefina Guilisasti estamos ante lo monumental de un acopio preciosista, encausados a hablar de naturaleza muerta, de bodegones, de lo decorativo tensionado por un arte que avanza con aplomo hacia tópicos y estéticas abordadas con puntualidad y convergencia. Desde sus primeras incursiones en exposiciones colectivas y su primera individual de Galería Praxis en el Santiago de 1989, instaló las bases del cuerpo de obra que hoy conocemos y que resulta ser tan cardinal como singular. Diría que lo importante de su trabajo es ese fundamento tan irreprochable. Que se ve en una presentación casi siempre neoclásica de sus instalaciones sostenidas por pilares que soportan a la vez pequeñas ruinas o vestigios de ruinas, materiales o modos de vida. Grandes afectos y grandes vacíos. "Son obras de gran formato. Creo que los artistas de los años noventa querían mostrarse en grande; no hay nada chico, mínimo, es todo enorme, se hace notar. Siento que tiene una poesía intrínseca. Todo esto del formato creo que tiene mucho que ver con que las galerías de esos años en Chile no te daban la oportunidad de mostrarte fuera del realizado de grandes proyectos". 
En un sistema de trabajo esquemático y continuo, Guilisasti representa objetos traduciendo sus materialidades. Al principio fueron objetos domésticos, como naturalezas muertas puestas en módulos múltiples; ahora son inmensos formatos de pintura y un gobelino, con representaciones históricas de expolios, archivos tan puntuales como universales. En pintura pasa del género menor al mayor, de la naturaleza muerta a la pintura histórica, pero con los sentidos volcados sobre lo mismo. Eso que en resumen podría ser un estudio de la cultura material, en el que la representación de esos objetos incorpora, según ella, "un aspecto menos evidente y doble, precisamente porque escinde esta escena clásica en función de un acercamiento a la existencia individual de ciertos componentes de ese mundo que sugieren procesos, historias privadas y comerciales, peregrinaciones, descubrimientos de territorios, etapas de colonización, explotación y desarrollo del capital."

\section{ANTONIA TAULIS:}

Tu obra es enorme. Te has dedicado a ordenar una gran cantidad de objetos y materiales a lo largo de tu producción. ¿Cuál es el registro que ronda esos objetos y materiales? ¿Es quizás existencial o emocional?

\section{JOSEFINA GUILISASTI:}

Sí, es una vasta obra de cuadros de gran formato, conformada por series compuestas desde entre 72 pinturas -La Vigilia (2001)- hasta 180 -El duelo (2011). En gran parte de mi obra mecanizo la realización de cada pintura en una producción masiva que expresa mi perspectiva pictórica de la cultura material y las artes decorativas (porcelanas, alfombras). Esto surge a partir de la cotidianidad y la cercanía que me sugieren estos objetos, los cuales empleo como registros de memoria, pues reconozco que también me liga a ellos una relación emotiva. Además, los objetos cotidianos que empleo se convierten en unidades que me permiten construir y reconstruir historias; de esta manera mi trabajo revaloriza la dimensión antropológica, histórica, cultural y socioeconómica que guardan los artefactos y que constituyen manualidades significativas para el desarrollo del capital (fig. 2).

\section{AT:}

Hay una memoria, pero ésta parece tener una relación afectiva o sensible con el objeto. En términos de memoria y política hay un montón de estéticas que rondan esos conceptos de forma más literal; sin embargo, el resultado de tu trabajo se presenta de una manera diferente y a la vez profunda, en el sentido de que habla de memoria desde lo visual. Se asoma algo de melancolía, ¿no? 
ENTREVISTA

Figura 2. Josefina Guilisasti, El Duelo, 2011, instalación de 180 pinturas al óleo de objetos comunes de porcelana, dimensiones totales: $2.90 \times 12.60 \mathrm{mt}$. Cortesía de la artista.

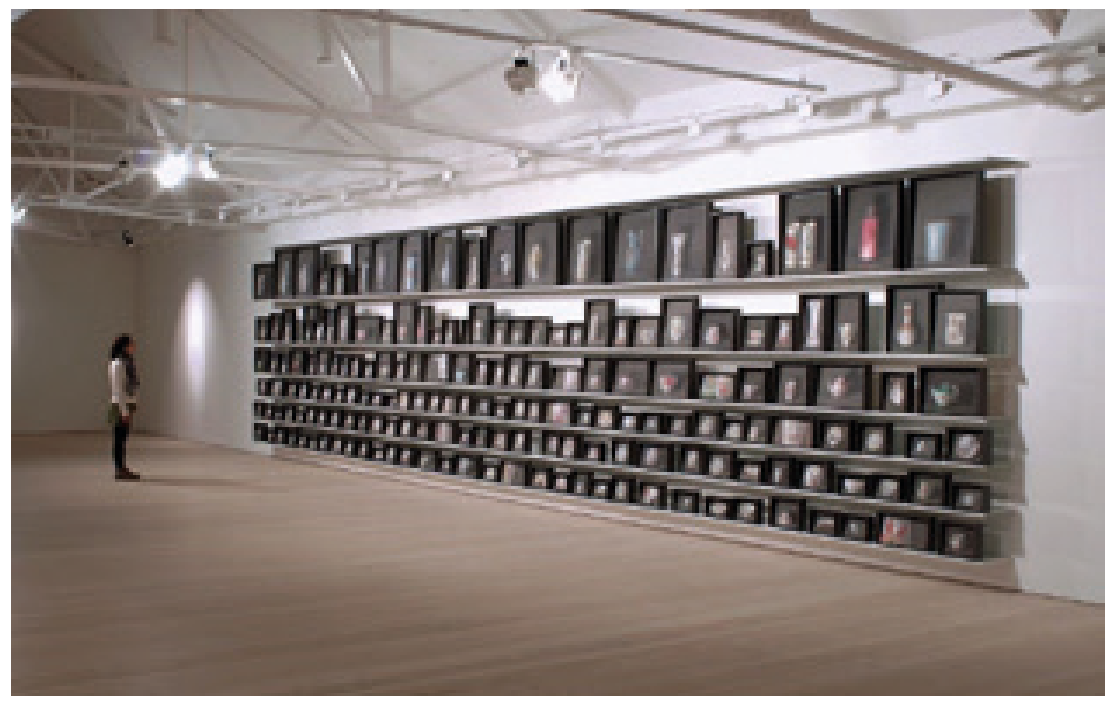

JG:

Mi obra es una mirada contemporánea del género de la Naturaleza Muerta y en este género la melancolía está presente. Muchas veces también represento objetos que están fuera de circulación, pero que han sido parte de una historia material pasada. En ellos el tiempo está detenido. En ese sentido, mi obra es para mí un acto de representación del pasado en permanente tensión con el aceleramiento de la sociedad actual. Esto otorga un sentido particular sobre la percepción de las cosas, haciéndolas más reposadas. Así, trabajar con el bodegón no pasa por la idea de estar al día, sino más bien de saber trabajar desde una economía de medios para crear un estado de detención: no ir con los tiempos sino en contra de ellos, de manera de crear una pintura que requiere de un tiempo (de contemplación) y un espacio (de exhibición) particular para el espectador contemporáneo.

\section{AT:}

Que se relaciona además con lo interior...

JG:

El género de la naturaleza muerta existe desde la antigüedad y se caracteriza por representar uno o varios objetos provenientes de la vida doméstica. Históricamente, el bodegón ha sido entendido por la academia como una materia menor, a causa precisamente de esta estrecha relación con el espacio doméstico. No obstante, este género lo que hace es rescatar aquellos objetos comunes, que paradójicamente "se dan el lujo" de no poseer ningún tipo de grandiosidad ni de narrativas. En estos bodegones, además, está ausente la figura humana. Desde ahí comienza mi trabajo. 
AT:

Sí, pero justamente a través de esa selección muy precisa de objetos íntimos y nimios caben problemas y asuntos humanos universales. $Y$ se propone desde ellos una seriedad que incluye preocupaciones que abordas en tus últimos trabajos, tales como el expolio y los robos.

JG:

En relación a Expolio, realizada en forma colectiva junto a Diego Martínez y Francisco Uzabeaga en el Museo de la Memoria, buscamos plantear desde el arte una reflexión acerca del robo de obras, empleando la pintura como medio expresivo. Mediante este ejercicio, en el que se exponen cuatro pinturas de gran formato, nos cuestionamos acerca de la dimensión objetual del arte, su valor de culto, el deseo por poseer obras, el modo en que éstas se transforman en artefactos capaces de dar identidad a los pueblos, y el daño que implica la pérdida de la memoria colectiva que se acumula en ese patrimonio (fig. 3,4 ).

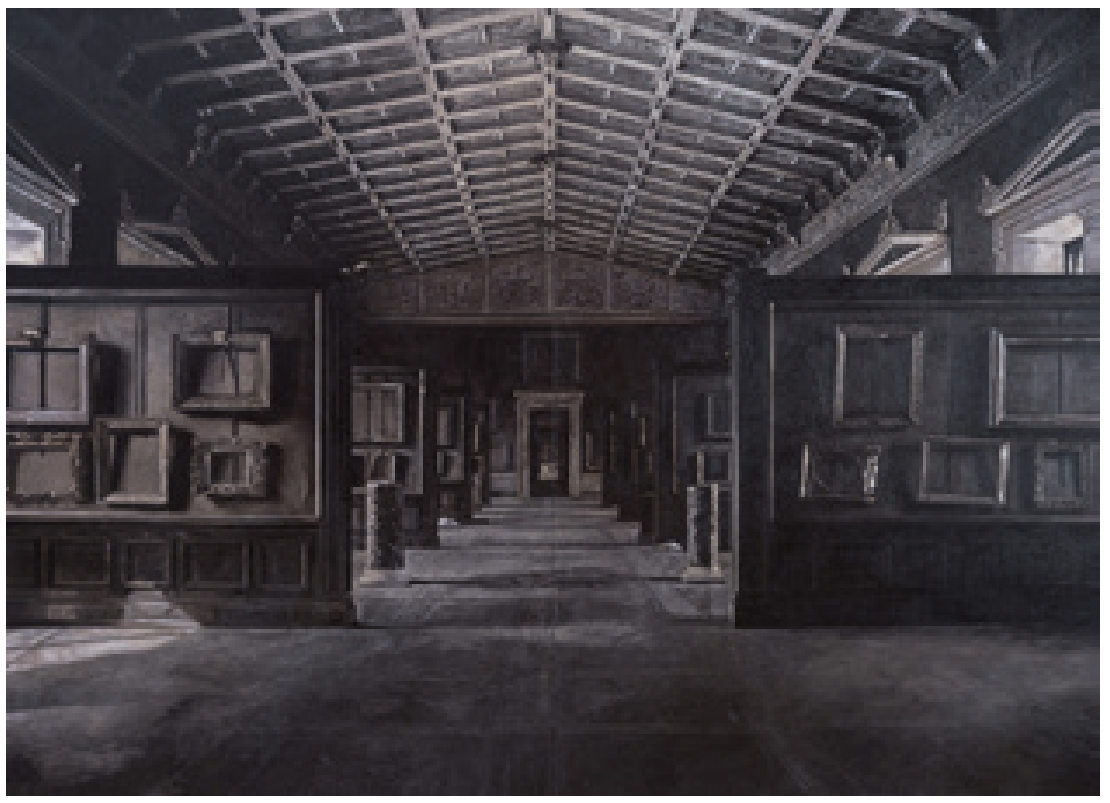

AT:

O sea que los problemas más universales que toca esta obra tienen que ver con esa macropolítica que implica la apropiación y los movimientos de poder...

JG:

A lo largo de la investigación que realizamos para llegar a la muestra, nos enteramos del estado de alerta en el que se encuentran algunos organismos internacionales encargados del resguardo del patrimonio cultural ante el comercio
Figura 3. Josefina Guilisasti, Diego Martínez y Francisco Uzabeaga, Museo Hermitage (Russia), 2014, óleo sobre tela, 4, 1 × 3 mt. Cortesía de la artista. 
Figura 4. Vista de la exposición Expolio, de Josefina Guilisasti, Diego Martínez y Francisco Uzabeaga, en el Museo de la Memoria y los Derechos Humanos, Santiago de Chile, 2015. Cortesía de la artista. ilícito de bienes extraídos en Iraq y Siria. La paradoja es que el Estado Islámico ha estado obteniendo ingresos a través del saqueo y venta de artefactos encontrados en sitios arqueológicos, situación que se ha encubierto mediante la publicidad obtenida a partir de la destrucción de los artefactos culturales más emblemáticos y que genera un alto impacto mediático.

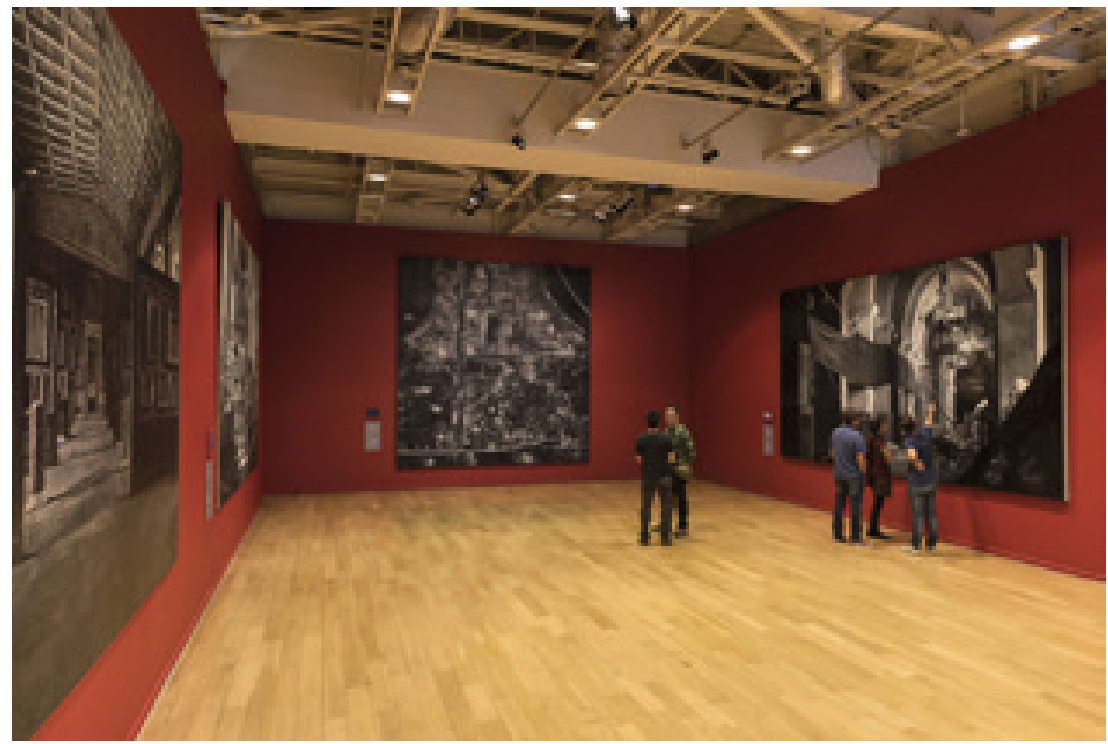

AT:

La investigación de Expolio fue distinta a la que te han exigido otros proyectos, como la intervención Objetos Light en el Museo de Artes Decorativas. En ésta última camuflas vaciados de silicona blanca simulando ser cerámicas entre las vitrinas: el objeto todavía es el protagonista. ¿Con la naturaleza muerta, cuando trabajas con objetos decorativos o utilitarios, marcas una diferencia social o de poder entre unos objetos que son más opulentos y decorativos que otros? (fig. 5)

JG:

Sí, totalmente. La primera obra que hice fue La Vigilia, una serie de pinturas de utensilios de aluminio dispuestas sobre un conjunto de estanterías con repisas. El objetivo de esta obra, más allá de la representación y el ilusionismo en la pintura, era llamar la atención en cuanto al tipo de menaje de uso más extendido en las casas chilenas. Por otro lado, El duelo, a través de la mecanización y producción masiva de las pinturas, apunta a la ruptura del concepto de la porcelana como "oro blanco", como objeto único y preciado por su contribución a la historia cultural y material de un pueblo. Por su parte, el uso de la silicona en Objetos Light supone en primer lugar una exploración en torno a las 
posibilidades que ofrece este material, cuya presencia en la cotidianidad está ampliamente extendida, y en segundo lugar, busco enfatizar la liviandad, elasticidad y capacidad de torsión que posee, propiedades que contrastan radicalmente con las características de la porcelana, que es la materialidad original de los artículos a partir de los cuales se obtuvieron los moldes expuestos. Tanto el aluminio como la porcelana y la silicona -las materialidades que aborda mi trabajo de series de estos últimos años- dan cuenta de objetos con utilidades y procedencias diferentes.

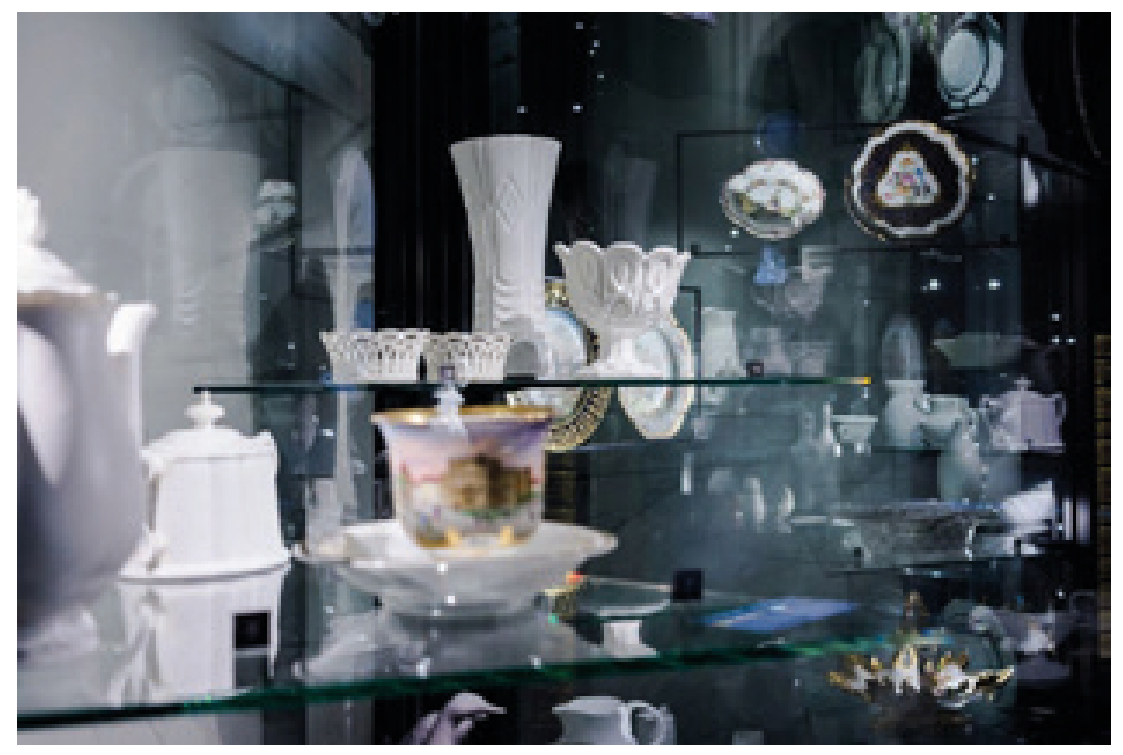

AT:

Al final, los objetos mismos que retratas son desarmados en su materialidad y en la obra quedan fundidos en los problemas del arte...

JG:

Exacto, quedan fundidos en torno al problema de la representación, su puesta en escena y la historia de la cultura material.

AT:

O sea que hay problemas materiales, pictóricos e históricos. A todo esto, siendo artista hiciste un posgrado en historia, ¿no?

JG:

Sí, no lo terminé, pero me dio herramientas para tener una metodología de investigación y así poder entrar mejor en temas específicos y darle más contenido a mi obra.
Figura 5. Josefina Guilisasti, Objetos Light, 2013, 60 piezas de silicona blanca y de colores traslúcidos, cuyos moldes han sido tomados de diferentes artículos antiguos hechos originalmente en porcelana. Vista de la instalación en el Museo de Artes Decorativas, Santiago. Cortesía de la artista. 
AT:

Eso se nota en tu libro Still Life 1998-2011, publicado por la editorial de Galería AFA, donde los textos abordan de manera muy bella la historia de los materiales. Los textos mismos de esta publicación marcan una diferencia en relación a lo escrito anteriormente sobre tu obra, siendo de corte más histórico y menos especulativo.

JG:

Still Life es un catálogo retrospectivo de mi obra. En él, efectivamente, se presenta una lectura más bien histórica de mi trabajo, pues durante el período que abarca el libro me dediqué principalmente a la reactualización y la resignificación de un género tradicional de la pintura: la naturaleza muerta. Además, últimamente he estado trabajando con Manuel Alvarado, historiador dedicado al estudio de la cultura material, quien ha colaborado conmigo desde el año 2014 en la elaboración de los discursos que sustentan mi obra.

AT:

Se ve que detrás de tu trabajo está el hacerse cargo de manera muy seria de los problemas que eliges tratar. $Y$ éstos pueden ser o parecer pequeños, pero la manera de trabajarlos, tanto visual como investigativamente, es bastante asidua y concienzuda.

JG:

A lo largo de mi carrera he procurado crear un relato coherente que logre articular las problemáticas históricas, estéticas y materiales abordadas en mi obra. Para conseguir esto, la preparación de mis trabajos incluye una investigación bibliográfica y documental previa, como la que realizamos para Expolio. Además de ello, el diálogo y trabajo con historiadores y teóricos ha resultado fundamental, ya que ha enriquecido la visión y contenido de mis obras.

\section{AT:}

En las lecturas sobre tu trabajo se da a entender que siempre fuiste una artista disidente respecto de algo, hay una discusión con algo, que puede ser la escuela de los ochenta, o ciertas estéticas en boga...

JG:

Soy formada en la Universidad de Chile y esa eventual disidencia podría provenir de mi paso por esa escuela. No me siento de la escuela de los ochenta. 


\section{AT:}

¿Y cómo ves tu trabajo en relación a las obras contemporáneas chilenas e internacionales?

JG:

Ha sido un trabajo muy personal. En cuanto a la investigación visual, he desarrollado una serie de procedimientos, entre los que destaco en primer lugar una revisión siempre atenta de la historia del arte, de la cual me apropio del género que abordo, por ejemplo, cuyos máximos referentes son para mí el español Sánchez-Cotán (1560-1627) y el italiano Giorgio Morandi (1890-1964).

\section{AT:}

¿Te has dedicado a la pedagogía?

JG:

Muy poco. Pero siempre estoy trabajando con artistas jóvenes. La retroalimentación en el trabajo con gente más joven es importante. Eso permite que respetemos los ritmos de trabajo, sin jerarquías, traspasándonos información, tanto ellos como yo, en una retroalimentación mutua.

\section{AT:}

Has desarrollado proyectos externos a tu obra. Estoy pensando por ejemplo en Incubo, proyecto de residencias curatoriales que fundaste con Cecilia Brunson. Incubo duró cinco años y en ese lapso trajeron a curadores de afuera, de manera que los artistas de Chile tuvieron acceso a otras lecturas y miradas de sus obras. Al respecto dijiste que lo que te importó fue el diálogo que se pudo producir y que querías que tu generación se oxigenara.

JG:

Incubo fue un proyecto de residencia realizado entre los años 2005 y 2010 , período durante el cual el contexto local requería que se produjera esta instancia. Permitió dar una cierta visibilidad a nuestro medio, por medio de la invitación de diferentes curadores y directores de museos para dialogar con los artistas locales. Pienso que fue un aporte relevante para abrir las discusiones y los puntos de vistas a otras miradas en torno al arte.

Por otra parte, junto a Voluspa Jarpa y Nury González sostuvimos por un período la galería Muro Sur, cerca del MAC Parque Forestal. Ésta fue una experiencia muy significativa, no solamente en cuanto a brindar un espacio de exhibición, sino también por las curatorías que se realizaron, que incluyeron la 
invitación de diferentes artistas locales, y cuyo resultado fue una exposición en Nueva York, en Americas Society, Ilamada Backyard (2003), en la cual participaron varios artistas de diferentes generaciones.

\section{AT:}

¿Qué puedes decir de la generación de los noventa, a la que perteneces?

JG: La generación de los noventa viene de un proceso de obra bastante complejo. Existen referentes muy diversos, provenientes de un contexto político fuerte, por lo tanto no es una generación tan ligada al mercado como las generaciones actuales. Es una generación que se ha concentrado en construir un cuerpo de obra y que actualmente está teniendo su visibilidad; es tiempo de que tenga un protagonismo.

\section{AT:}

Hay una artista de tu generación, que quizás no sea la única, pero que es la que personalmente se me vuelve más patente, con la que ocurren muchos cruces en relación con tu obra: Livia Marín. Sus trabajos comparten eso de los supuestos temas menores, domésticos y femeninos, y la fragmentación en instalaciones grandes.

JG:

Livia Marín es una artista cuya obra me interesa mucho. Su trabajo se ha caracterizado por las instalaciones a gran escala y la apropiación de objetos de producción y de consumo; tenemos varios cruces.

AT:

¿Cuál es el camino que va a seguir tú investigación?

JG:

Me interesa actualmente poner en contexto mi obra dentro del espacio de exhibición, es por eso que estoy mostrando en instituciones donde la obra dialoga directamente con la colección permanente.

AT:

¿Qué estás preparando ahora?

JG:

Ahora estoy preparando una exposición que se realizará en el Museo de Arte Precolombino, llamada Caída Libre. 
Studio Visit realizada en el marco de la Sesión Antenna del 28 de abril de 2016. Artishock es Media Partner de Antenna, una organización que crea vínculos entre el mundo del arte y la sociedad con el fin de construir y difundir la identidad cultural de Chile. Apoya a artistas y creativos en la gestión y desarrollo de proyectos de arte e investigación artística. Construye comunidad en torno al arte y opera gracias al apoyo de sus miembros.

Antonia Taulis Nace en Santiago de Chile, en 1989. Es crítica de arte y artista visual. Licenciada en Teoría e Historia del Arte por la Universidad de Chile, actualmente es Asistente de Dirección de Galería Madhaus, y redactora en las revistas Artishock y Joia Magazine. Ha escrito para decenas de exposiciones y catálogos y trabaja para otros proyectos independientes.

\section{Antonia Taulis}

Nasceu em Santiago do Chile, em 1989. É crítica de arte e artista visual. Licenciada em Teoria e História da Arte pela Universidade do Chile. Atualmente é Assistente de Direção da Galería Madhaus e redatora das revistas Artishock y Joia Magazine. Já escreveu para dezenas de exposições e catálogos e trabalha para outros projetos independentes.

\section{Josefina Guilisasti}

Nasceu em Santiago do Chile, em 1963. Formada em 1985 em Licenciatura em Artes, com ênfase em Pintura, na Facultad de Arte de la Universidad de Chile. Em 1990 realizou estudos de restauração em pintura em Milão e, em 1991, um curso de pintura cenográfica no teatro Scalla de Milão. De 2005 a 2009 desenvolveu o projeto Incubo juntamente com a curadora Cecilia Brunson. Participou de inúmeras exposições nacionais e internacionais. Já recebeu diversos prêmios e seus trabaIhos já integram as coleções de museus importantes como o Museo de Arte Contemporáneo, Santiago, Chile e Blanton Museum, Austin - Texas, USA. Dentre as exposições coletivas internacionais, é preciso salientar sua participação nas Bienais do Mercosul, em Porto Alegre/RS, Brasil, em 2001 e em 2007.

(*) Texto enviado em março de 2018 